\title{
UMA INVESTIGAÇÃO A PARTIR DO PENSAMENTO DE GUSTAV RADBRUCH: A PROPOSTA DE SUPERAÇÃO DA "INJUSTIÇA EXTREMA" ATRAVÉS DA NECESSIDADE DE (RE)CONSTRUÇÃO CONCEITUAL DO DIREITO
}

\author{
Cristian Kiefer Da Silva ${ }^{1}$
}

\section{RESUMO}

Este artigo faz uma análise substancial acerca da concepção do direito em Gustav Radbruch, procurando destacar, dentre outros aspectos, a "injustiça extrema". É peremptório afirmar que para o grande jurista alemão, a questão da obediência à lei não se resolve pela força, como afirma a tradição. A pergunta essencial não é por que obedecer à "lei injusta", mas porque se apoia na "lei injusta", obedecendo-a. Ora, tudo isto significa a rigor, que a positividade no direito se contenta com a validade formal das normas jurídicas, quando todo o problema se situa numa esfera mais profunda, correspondente ao valor ético do direito. Inclusive, a ausência de justiça não aflige apenas o sistema jurídico, mas outros sistemas sociais apresentam injustiças gritantes.

PALAVRA-CHAVE: FILOSOFIA DO DIREITO; ARBITRARIEDADE LEGAL; DIREITO SUPRALEGAL; RACIONALIDADE; INJUSTIÇA EXTREMA.

\section{AN INVESTIGATION FROM THE THOUGHT OF GUSTAV RADBRUCH: THE PROPOSAL TO OVERCOME THE "EXTREME INJUSTICE" THROUGH THE NEED TO CONCEPTUAL (RE)CONSTRUCTION OF THE RIGHT}

\begin{abstract}
This article makes a substantial analysis about the conception of law in Gustav Radbruch, seeking to highlight, among other aspects, the "extreme injustice". It is peremptory to say that for the great German jurist, the question of obedience to the law is not resolved by force, as tradition states. The essential question is not why obey the "unjust law", but why it relies on the "unjust law", obeying it. All this means strictly speaking, that positivity in law is satisfied with the formal

\footnotetext{
${ }^{1}$ P Pós-Doutor em Direito pela Pontifícia Universidade Católica de Minas Gerais. Doutor em Direito pela Pontifícia Universidade Católica de Minas Gerais. Mestre em Direito pela Pontifícia Universidade Católica de Minas Gerais. Especialização em Direito Processual Civil Aplicado pelo CEAJUFE. Especialização em Direito Público Aplicado pelo EBRADI. Especialização em Direito Tributário pelo ÊNFASE. Graduação em Direito pela Universidade José do Rosário Vellano. Graduação em Administração pela Pontifícia Universidade Católica de Minas Gerais. Visiting Research Scholar na Northeastern State University-EUA. Visiting Foreign Professor na University of Tulsa-EUA. Visiting Foreign Professor na Oklahoma State University-EUA. É Professor Adjunto da Escola de Direito do Centro Universitário UNA. É Professor na Graduação e na Pós-graduação em Direito da SKEMA Business School. É Professor Titular da Escola de Direito da Faculdade de Minas (Faminas-BH). É Professor da Pós-Graduação em Direito do Instituto Universitário Brasileiro (IUNIB). É Pesquisador voluntário no INSEPE (Instituto de Ensino, Pesquisa e Extensão). É membro associado e avaliador do Conselho Nacional de Pesquisa e Pós-Graduação em Direito (CONPEDI). É membro associado da Sociedade Brasileira para o Progresso da Ciência (SBPC). Participa com frequência de fóruns jurídicos, projetos e atividades acadêmicas relacionadas à organização de seminários, congressos, minicursos, grupos de estudo e pesquisa. Tem atuação na área de Direito, com ênfase em Direito Público, Direito Processual e Teoria do Direito. Mediador e Conciliador Judicial cadastrado no CNJ. Membro do corpo de avaliadores do MEC no BASIS/INEP.
} 
validity of legal norms, when the whole problem is situated in a deeper sphere, corresponding to the ethical value of law. Even the absence of justice not only afflicts the legal system, but other social systems present glaring injustices.

KEYWORD: PHILOSOPHY OF LAW; LEGAL ARBITRARINESS; SUPRALEGAL LAW; RATIONALITY; EXTREME INJUSTICE.

\section{INTRODUÇÃO}

Do ponto de vista da ciência do direito, pensou-se durante muito tempo, e por vezes ainda se pensa, que a pergunta sobre "o que é a justiça" e a questão de "como se conhece a justiça" deveria ser respondida completamente independente uma da outra. Nesse aspecto, o grande problema da "injustiça das leis" torna-se um tema central deste trabalho, principalmente porque é intenso o contraste entre os valores do ordenamento jurídico positivo e o sentimento de justiça preponderante na sociedade.

De fato, quem quer empenhar-se em compreender o lugar e o papel do direito nas sociedades humanas, não deve menosprezar nenhuma de suas dimensões precedentes. Portanto, para eliminar as incertezas e os equívocos que se acumularam ao longo dos séculos pela ausência de uma problematização coerente das estruturas jurídicas das sociedades humanas, é preciso, antes de mais nada, arrancar o direito do magma das dúvidas e das polêmicas.

$\mathrm{Na}$ verdade, isso é uma tarefa difícil, pois sob o peso esmagador das tradições, não é uma escolha entre o verdadeiro e o falso, ou entre o válido ou inválido que convém realizar. Decerto, trata-se de avançar em meio às tensões e conflitos entre o que é e o que deve ser, que não só se estabelecem e desaparecem apenas para renascer em seguida, mas habitam a própria razão em seu esforço arquitetônico de regulação das condutas humanas.

Como se sabe, o positivismo jurídico produziu, com efeito, as grandes obras legislativas do início do século XIX, porque o legislador de então ainda se conduzia por uma forte consciência moral, pressuposto este que, porém, já não se verificou nas ditaduras do nosso tempo. O fato é que as leis ultrajantes deixaram de ser meros exemplos e passaram a ser realidade, ou seja, o conceito de lei puramente formal fracassara.

Por sua vez, após o monstruoso e arbitrário domínio nacional-socialista, em que o direito 
foi pervertido até se tornar irreconhecível, muitos pensavam que logo após a Segunda Guerra Mundial, deveriam regressar novamente ao direito natural. Em contrapartida, o renascimento do direito natural foi muito criticado na prática, e de fato também não foi um renascimento da racionalidade e do bom senso, mas a crítica atinge propriamente a ciência, especialmente a filosofia do direito, que não tinha de todo preparado a jurisprudência para o fenômeno da "injustiça legal".

Por isso, é correto dizer que a fonte jurídica por excelência deve ser alicerçada nos princípios reitores do direito, de maneira a se opor totalmente à "injustiça das leis" que, por iníqua, contrarie tais princípios, os quais garantam de certo modo a juridicidade ético-política do próprio sistema. Assim, a ideia de lei não deve ser exterior ao próprio ser humano, pois é preciso superar a miséria jurídica herdada do nacional-socialismo, combatendo o arbítrio no pensamento jurídico através da tutela de um direito indisponível, ou seja, aquele que a lei considera essencial à sociedade e tem proteção pelo Estado.

Certamente, um impulso essencial para a renovação do conceito de direito surge com Gustav Radbruch, salientando que no direito, ao lado dos conceitos classificatórios e que apenas admitem de tudo ou nada, entram numerosos conceitos ordenadores que admitem um compromisso mais ou menos, de onde se segue que não há uma só e única solução correta, mas várias soluções corretas, isto é, defensáveis, plausíveis e suscetíveis de consenso.

\section{POSIÇÕES FUNDAMENTAIS EM GUSTAV RADBRUCH ACERCA DA POSITIVIDADE NO DIREITO}

De fato, por toda a parte se levantava um combate contra o positivismo a partir da ideia de que há "leis que não são Direito e que há Direito acima das leis" (RADBRUCH, 2010, p. 159). Não há dúvidas de que naquela época o positivismo jurídico com o seu lema "acima de tudo deve-se cumprir as leis" reinou de modo absoluto entre os juristas. Na visão de Gustav Radbruch tem-se que:

O positivismo deixou [...] desarmados os juristas alemães ante as leis de conteúdo arbitrário e injusto. [...] Com isso se ficava sem a possibilidade de estabelecer a validez jurídica das leis. É certo que o positivismo pensa haver provado a validez de uma lei pelo fato de ter a força suficiente para lhe impor. [...] É certo que, independentemente do seu 
conteúdo, toda lei positiva leva consigo um valor: porque sempre será melhor que a total ausência de leis, ao dar lugar à segurança jurídica. Mas a segurança jurídica não é o único, nem sequer o valor decisivo que tem de realizar o Direito. Ao lado da segurança jurídica, há outros dois valores, que são o da utilidade e o da justiça. A hierarquia destes valores assinala o último posto para a utilidade com respeito ao bem comum. De nenhum modo se há de admitir que é Direito tudo o que é útil ao povo, mas que ao povo é útil [...] tão-só o que é Direito, o que traz segurança e tende à justiça. A segurança jurídica, que corresponde a qualquer lei já pelo fato de sua mesma positividade, ocupa um lugar intermediário entre a utilidade e a justiça; a exige, por um lado, o bem comum, e por outro, a justiça. [...] Quando há um conflito entre a segurança jurídica e a justiça, entre uma lei que falha em seu conteúdo, mas que é positiva, e um Direito justo, mas que não adquiriu a consistência da lei, estamos realmente frente a um conflito da justiça consigo mesma, um conflito entre a justiça aparente e a verdadeira. (RADBRUCH, 1971, p. 159).

Nessa perspectiva, objeta-se que com o fim da Segunda Guerra Mundial e a queda do Terceiro Reich, as cortes alemãs receberam o intenso desafio de se manifestar sobre o direito nazista e suas consequências. Em tal período, a lista de monstruosidades cometidas se enquadrava em um catálogo de horrores, e nenhum meio-século testemunhou tanto massacre em escala, crueldades, desumanidades, condenação de povos inteiros à escravidão e aniquilamentos de minorias. Nessa investigação, orienta Gustav Radbruch que:

Não se pode ignorar - precisamente depois da experiência destes doze anos - os terríveis perigos para a segurança jurídica que podem acarretar atitudes representadas pelo conceito de arbitrariedade legal ou pela negação da natureza jurídica às leis positivas. Esperamos que tais injustiças permaneçam como um erro e uma confusão isolados do povo alemão. Mas, de qualquer modo, precisamos estar preparados, buscando a superação essencial do positivismo que fez esmorecer o poder de defesa contra o abuso da legislação pelos legisladores nacional-socialistas e lutando contra o retorno de modalidades de Estado da mesma forma injusta ${ }^{2}$. (RADBRUCH, 1957, p. 66).

Pois bem, a perseguição implacável de adversários políticos, a selvageria na busca da vitória, o saque, o derramamento de sangue, o estupro e o assassinato por parte de uma soldadesca brutalizada, foram traços marcantes de um período onde reinava a "injustiça extrema". É horrível que tivessem que ocorrer no século XX, e no coração da Europa, mas não estavam fora dos padrões reconhecidos do comportamento humano. O processo sistemático, prolongado e burocraticamente controlado de exterminar milhões de vítimas que não ofereciam nenhum perigo e cuja morte não dava nenhuma vantagem aos assassinos, só podia ser interpretado como a manifestação de uma mente enferma; e toda a nação alemã parecia estar afetada pela doença imposta por um regime não democrático.

Nesse contexto, o exame dos conceitos positivistas de direito mostra que, no âmbito do

\footnotetext{
${ }^{2}$ Friedrich Buchwald também defende a idéia de um direito supralegal (BUCHWALD, 1946, p. 8).
} 
positivismo jurídico, posições muito distintas são defendidas (comum a todas elas é apenas a tese da separação entre direito e moral). Se houvesse certeza de que a tese positivista da separação é correta, a análise do conceito de direito poderia limitar-se inteiramente à questão acerca da melhor interpretação dos elementos da eficácia e da legalidade, bem como da melhor forma de relacionar esses dois elementos. Por isso, cabe perguntar se um conceito positivista de direito é realmente adequado como tal.

\section{A (IN)DECISÃO PROBLEMÁTICA A RESPEITO DO CONCEITO DE DIREITO}

Adentrando nas vias mais sutis da fundamentação do direito alemão, é importante registrar que o nacional-socialismo assegurou a sujeição de cidadãos, por um lado, e dos juristas, por outro lado, sobre a base dos princípios "as ordens são ordens", que se aplicava aos primeiros, e "antes de tudo hão de cumprir as leis", que se referia aos segundos. O grande lema projetado na mente dos alemães de "as ordens são ordens" não regeu nunca sem limitações. Entretanto, durante séculos, o positivismo jurídico se impôs quase sem nenhuma contradição entre cidadãos e juristas alemães. Assim, "falar de leis que não constituíram direito era uma contradição igual falar de um direito que estivera acima das leis" (RADBRUCH, 2010, p. 155).

De acordo com a tese radbruchiana, pode-se preconizar que o fundamento axiológico do direito (ideia formal) seja realmente levado em conta quando da aplicação judicial, e assim conceder uma interpretação diferente da mera aplicação da positividade como forma de concretização do direito. Por seu turno, a conotação do termo direito, polivalente ao extremo, exclui a possibilidade de uma resposta clara e definitiva à pergunta, qual seja: “o que é direito?”. Para que se possa entender melhor a arbitrariedade legal e o direito supralegal em Gustav Radbruch, torna-se importante estabelecer as linhas definitórias do conceito de direito, sendo certo que "a tarefa do jurista consiste apenas em indagar o que é direito, e nunca se ele é justo" (RADBRUCH, 1999, p. X). No que se refere à indecisão problemática de tal conceito, Simone Goyard-Fabre explica que:

Em sua persistência, o pluralismo semântico da palavra direito decerto não é acidental. Ele corresponde à ambiguidade essencial de seu conceito: na verdade, a multiplicidade de relações que o direito mantém com outros campos da existência humana mostra a dimensão da dificuldade existente para circunscrever seu campo próprio, o que obsta a 
um empreendimento de definição rigorosa. Tanto em sua extensão como em sua compreensão, o conceito de direito se mostra rebelde ao aclaramento. (GOYARDFABRE, 2007, p. XVIII).

Decorre daí que, nesse campo de compreensão multidimensional e complexo, o termo direito corresponde a um conceito vago, de difícil definição com rigor. Porém, apesar das incertezas na definição de um conceito claro acerca do direito, Gustav Radbruch entendia que a grande missão do ordenamento jurídico era a segurança jurídica e a paz, sendo a segunda missão a justiça. Por isso, os horrores do nazismo fizeram-no modificar, ou, para alguns, desenvolver o seu pensamento a respeito do direito $^{3}$ a partir daí. Portanto, não é o propósito deste trabalho examinar o percurso genealógico do direito em seus vários momentos, mas é importante considerá-lo do ponto de vista filosófico, na medida em que o olhar crítico que perscruta a compreensão do direito revela a problematicidade vinculada à sua evolução.

Pode-se sustentar que a maturação semântica do pensamento racional procurou dar ao direito um contorno distinto, cuja remota inserção na ordem natural das coisas estava longe de deixar imaginar uma possível autossuficiência. As reviravoltas filosóficas contribuíram muita para apurar o conceito de direito, arrancando-o de seu invólucro impermeável. E tal esforço na elucidação do seu sentido se deu por etapas com modificações diferenciadas de maior ou menor eficiência. Não obstante, várias foram as tentativas de se sustentar em uma vontade de cientificidade a sistematização de um “direito universal” (GOYARD-FABRE, 2007, p. XX). Esse ideal de cientificidade foi compartilhado por várias gerações, no entanto, apesar desse esforço de

\footnotetext{
${ }^{3}$ Um debate que cerca a figura de Gustav Radbruch é aquele entre os que defendem a descontinuidade da obra do autor, nos períodos antes e Pós-Guerra, e entre aqueles que defendem a continuidade. A suposta descontinuidade de Gustav Radbruch, após o terror nacional-socialista e o Holocausto, poderia ser atribuída ao advento da filosofia existencialista e ao renascimento da teologia na vida intelectual e espiritual alemã. Parte dos estudiosos da obra do autor afirma que Gustav Radbruch abandonou o relativismo e o racionalismo de sua primeira fase em prol do direito natural do reconhecimento de que a justiça deve prevalecer sobre a segurança jurídica e eficácia do direito. Por sua vez, aqueles que defendem a continuidade da obra apontam para um desenvolvimento natural do seu pensamento, uma vez que Gustav Radbruch nunca considerou suas últimas obras como retificadoras de seus primeiros escritos (MARTÍNEZ BRETONES, 2003, p. 11-12). Stanley L. Paulson é exemplo dos que defendem a tese da não ruptura: "Radbruch não poderia ter sido 'convertido' em relação ao positivismo jurídico [...]. Nos primeiros tempos, Radbruch já defendia um critério de base no sentido de que 'a lei é realidade cujo significado (Sinn) é para servir à justiça". Tradução livre do inglês: "Radbruch could not have been 'converted' from legal positivism [...]. In his earlier period, Radbruch had already defended a basal criterion to the effect that 'law is the reality whose meaning (Sinn) is to serve justice" (PAULSON, 2006, p. 19). Rodolfo Luis Vigo, entretanto, é um exemplo daqueles que percebem uma descontinuidade: "Os artigos escritos na década de quarenta apontam inequívocas transformações em aspectos substanciais que resultam decisivos para coincidir com aqueles que apontam uma descontinuidade no autor em estudo". Tradução livre do espanhol: "Los artículos escritos en la década del cuarenta señalan inequívocas transformaciones en aspectos substanciales que resultan decisivos para coincidir con aquellos que señalan una discontinuidad en el autor en estudio" (VIGO, 2006, p. 15).
} 
reforma intelectual, o aclaramento do termo direito ainda é bastante precário. Para explicar isso, Simone Goyard-Fabre aduz o seguinte:

Em suma, o conceito de direito está dividido: por um lado, impõe-se as perspectivas racionais de uma eventual codificação que lhe implicaria homogeneização; por outro, o pluralismo dos costumes regionais resiste, com sua carga pitoresca e de eficácia. Portanto, embora haja um despertar da racionalidade jurídica, que busca a especificidade irredutível subsumida no termo direito, ela está às voltas com duas tendências antagônicas - a sistematização e a casuística -, que dão ao direito duas feições incompatíveis. Como a multiformidade do direito engendra-lhe multivocidade, seu conceito permanece indefinido e incerto. (GOYARD-FABRE, 2007, p. XXI).

Ademais, é suficiente indicar que a elucidação do conceito de direito passa por uma constante e necessária mutação, ainda mais em Gustav Radbruch, que no prólogo de sua obra Injustiça Legal e Direito Supralegal (Gesetzliches Unrecht und übergesetzliches Recht, 1946), comenta Maria Isabel Azaretto de Vásquez que:

A experiência nacional-socialista produz uma tal impressão nele, que o obriga a repensar seu anterior positivismo, e esta reflexão o leva a rechaçá-lo, já que vê na separação do direito e da moral a base em que se apoiou o nazismo para levar a cabo, sob a aparência de legalidade, as maiores injustiças. A formação positivista dos juízes e advogados os inabilitou para defender-se contra a legalidade injusta. Isto leva Radbruch a sustentar que uma lei que contrarie os princípios básicos da moralidade não é direito, ainda que seja "formalmente válida". (RADBRUCH apud VÁZQUEZ, 1962).

Evidentemente, o sentido e o valor do termo direito não devem ficar à margem da incompreensão, pois coteja-se que apenas uma análise realizada segundo os procedimentos da razão humana é capaz de depreender o significado do termo direito. Categoricamente, o direito deve ser reportado à razão humana como sua verdadeira fonte para atingir a clareza e a distinção de seu conceito. Para exemplificar melhor isso, Simone Goyard-Fabre acentua que "inseparável do invólucro metafísico que o prende, o termo direito não se livra do peso de sobrecargas e de sobredeterminações que dão origem à sua equivocidade" (GOYARD-FABRE, 2007, p. XXIV).

Apesar das modificações mais ou menos modulares na designação do direito como um corpo de regras que administram a sociedade, a legalização do direito, a proliferação das decisões judiciais, a insistência na concepção do direito como sistema de mandamentos e de regras, o crescimento avassalador do poder autoritário e arbitrário, as reivindicações cada vez mais numerosas apresentadas pelos diversos sujeitos de direitos (individuais e coletivos); são outros tantos traços e sintomas do positivismo jurídico. É preciso ressaltar que é "nesse desvio que 
residem os equívocos insuperáveis de um pensamento teorético que suas contradições internas tornam manifestos" (GOYARD-FABRE, 2007, p. 101). Além disso, é necessário distinguir também o que originariamente o pensamento germânico entendia sobre a positividade no direito. De acordo com Simone Goyard-Fabre:

O positivismo se pretende a-filosófico; mas é impossível ganhar essa aposta, pois a autossuficiência de uma teoria que, em sua pretensa "neutralidade axiológica", se limitasse apenas à fenomenalidade do direito é uma ilusão. Por outro lado, afastando do campo jurídico toda normatividade transcendente, essa teoria jurídica - que tem forte propensão a rebaixar o direito, aquém de suas próprias prescrições, ao plano das condições empíricas, sociais ou históricas que as motivaram - redunda contraditoriamente afirmando a autonomia do direito na negação do caráter especificamente jurídico do direito. Por fim, a construção de um direito que, invocando critérios de racionalidade científica, se fechasse dentro das grades de uma legislação abstrata de alcance mais ou menos geral, teria fortes chances de gerar uma sistematização do direito rígida e sem vida. (GOYARD-FABRE, 2007, p. 101).

Por conseguinte, a acusação geral que fizeram a Gustav Radbruch, por entender que o positivismo jurídico preparou o terreno fértil para a legitimação dos regimes nazifascistas postura que ficou conhecida como reductio ad Hitlerum (redução a Hitler ou argumento aos nazistas) - é incoerente, mesmo porque o que aqui se pretende discutir é se houve uma real vinculação entre a postura científico-descritiva do juspositivismo e a instauração de regimes de exceção. Como isso foi bem sinalizado em capítulos anteriores, de maneira a reforçar tal compreensão, explica Andityas Soares de Moura Costa Matos que:

[...] a maior parte das teorias juspositivistas não se adapta a ambientes políticos autoritários, uma vez que o positivismo jurídico tem em alta conta aspectos técnicos do direito que não se coadunam com regimes de exceção. Trata-se dos valores de ordem, da igualdade formal e da certeza jurídica. Os sistemas autoritários, por seu turno, sempre se apresentaram como superiores à limitada racionalidade juspositivista, encarnando um tipo de justificação quase divina. Nesse sentido, recordemo-nos que a ideologia jurídica nazista era contrária ao juspositivismo, visto que, antes de consultar a lei, caberia ao juiz nacional-socialista decidir com base nos interesses políticos do povo, i. e., do Estado. (COSTA MATOS, 2009, p. 28).

De tal maneira, sobrepondo-se às imprecisões em torno do positivismo jurídico, o que deve ficar claro em Gustav Radbruch é que o positivismo jurídico foi incapaz teoreticamente de impor o seu projeto de cientificidade, porque, apesar desse fracasso, ele ainda assim traçou o perigoso caminho pelo qual vários autores enveredaram, embora a própria essência do direito estivesse em perigo. 


\section{O DIREITO EM BUSCA DE SEU SENTIDO EM GUSTAV RADBRUCH: A APROPRIAÇÃO DOS DIREITOS PELO DIREITO}

A questão central da análise do direito em Gustav Radbruch é que as leis extremamente injustas perdem sua característica de leis, não podendo ser aplicadas em discussões jurídicas. Por isso, a respeitável fórmula de Gustav Radbruch é construída para orientar a análise e aplicação do direito em situações difíceis e insuportavelmente injustas, onde o conflito entre justiça material e segurança jurídica estejam absolutamente identificados. Por outro lado, a fórmula radbruchiana atenta para os perigos da "injustiça extrema", e o seu ponto de partida é constituído por um conhecimento da metodologia jurídica, sobre o qual há unanimidade entre positivistas e nãopositivistas, e que deve ser admitida em razão dos deveres que lhe impõe a defesa da dignidade humana. Nesse sentido, para Enrique Dussel a "legalidade da injustiça" ou a "imoralidade legal" faz recordar que "o grupo ou pessoas dominantes fizeram de sua dominação o fundamento da lei" (DUSSEL, 1977, p. 80), maquiando o fato de a ordem vigente ser imposição de uma dominação legalizada.

A fundação do direito em pleno regime nazista apresentou uma perpetuação da lógica de dominação e episódios de banalização da violência, anunciando um fenômeno que não se pode dar por concluído devido a seus efeitos metajurídicos que perduram no tempo e no espaço. Contudo, o período compreendido pelo terror na Alemanha nazista, operou uma intimidação coletiva que, em conjunto com os mecanismos de propaganda, produziram uma modificação profunda no sistema de ideias e valores dominantes na sociedade. Foi em decorrência a isso, que Gustav Radbruch construiu uma fórmula de compatibilização entre a positividade e a justiça para tentar refundar o direito e coibir os avanços da "injustiça legal".

Por sua vez, cabe assinalar que a ideia de direitos humanos veio a se impor com uma força cada vez mais intensa, reconhecendo que tais direitos deveriam ganhar autoridade jurídica devido ao seu enraizamento na própria natureza humana. Nesse aspecto, afirma Simone GoyardFabre que "os direitos necessitam da mediação do direito para adquirir um valor jurídico que não possuem por si sós" (GOYARD-FABRE, 2007, p. XXXIV). Essa ideia de direitos humanos é bastante evidente em Gustav Radbruch, onde Fábio Henrique Araújo Martins reforça que: 
Sem a violência oficial para dar suporte ao controle das opiniões, será a impunidade democrática o maior responsável pela banalização e disseminação da impunidade por violação de direitos humanos, num dispositivo coletivo de internalização do silêncio social e dos mal entendidos políticos. [...] a "violência abismal" da impunidade destrói a possibilidade de ressignificação simbólica e institucional da democracia, engendra desde o silêncio oficial o catastrófico fracasso do direito e a suspensão da justiça. (MARTINS, 2011, p. 49-50).

Nesse contexto, o que Gustav Radbruch procura subsumir em sua teoria é a construção de um direito supralegal, um direito situado acima das leis, transpositivo, fundamentado na moral, semelhante à verdade, à beleza e ao bem comum; um direito superior, ao qual o direito positivo seja obrigado a ceder quando os dois entrarem em conflito. E para isso, cria uma fórmula que vai da absoluta incognoscibilidade essencial do direito à absoluta fé na justiça, reconhecendo como indispensável à solução das grandes questões do direito. A arquitetura do terror manifestada em pleno regime nazista fez com que Gustav Radbruch repensasse a respeito do verdadeiro conteúdo do direito. O jusfilósofo deliberadamente combateu as teorias anarquizantes que contrapunham os direitos ao direito, o antijuridismo puramente ideológico que visava o desaparecimento do Estado, a falência do ser humano e das próprias instituições antidemocráticas. Além disso, era totalmente contrário a vontade do Führer estampada na frase: "o terror sob a forma de lei".

Do ponto de vista teórico, Gustav Radbruch teve coragem e honestidade intelectual na busca de um sentido claro para o direito. Como tal, para ele, é importante sublinhar que o sentido do termo direito ganha força em sua teoria como um direito crédito, sendo que o Estado é o devedor perante quem os indivíduos e os grupos afirmarão doravante pretensões ou a quem endereçarão reivindicações. Nesse sentido, é nítido verificar que o que há de inalienável no direito à dignidade humana, implica, enquanto direito autenticamente jurídico, que este deve ser assumido pelo direito positivo estatal. O que Adolf Hitler fez, em pleno regime nazista, foi extirpar todas as garantias impostas aos cidadãos com a criação de uma espécie de "lei de seleção natural" que regeria a história e as relações entre todos os povos e Estados. Sabe-se, pois, que o Estado intervencionista contém inevitavelmente os germes do totalitarismo, como explica Simone Goyard-Fabre:

De fato, embora seja verdade que a operação mental de definir consiste em exprimir a essência ou a quididade de uma coisa, é preciso primeiro afastar confusões ou amálgamas para deixar claro o conceito de direito. Conclui-se, pois, que o direito não se 
confunde com a força: a força é poderio; ceder à força é um ato de necessidade em que o direito não entra. No entanto, deve-se notar que o direito necessita da força legal para se fazer respeitar. Convém por conseguinte ser mais preciso: é a violência enquanto expediente passional e tumultuoso que, por natureza, exclui o direito. Nesse sentido, a expressão "o direito do mais forte" é uma contradição nos termos e puro sofisma. Ainda assim, o conceito do direito não revela sua essência. (GOYARD-FABRE, 2007, p. XXXIX).

Na verdade, essa maneira de compreender o direito é no fundo banal, tendo em vista que por mais forte que seja essa orientação, "ela não conduz a uma definição pertinente, dando azo a uma concepção dogmática e sistemática do direito em que o discurso, as ferramentas metais, o raciocínio e a prática ocultam a realidade viva do mundo jurídico" (GOYARD-FABRE, 2007, p. XXXIX). Nessa dimensão, para compreender a teoria do direito exposta por Gustav Radbruch, é preciso superar a apropriação dos direitos pelo próprio direito. Muito embora isso pareça ser tarefa fácil, proclamar o direito aos direitos é decerto uma obsessão do jurista na contemporaneidade, que em seu íntimo e audacioso plano de superação das contingências, tenta de todo modo certificar "o progresso do direito". Por seu turno, conclui-se que de acordo com o jusfilósofo, "o direito é a realidade que tem o sentido de servir ao valor jurídico, à ideia do direito" (RADBRUCH, 2010, p. 47).

\section{CONSTRUINDO UMA CONCEPÇÃO DE DIREITO EM GUSTAV RADBRUCH: A CONTEMPLAÇÃO VALORATIVA DO DIREITO ENQUANTO REALIZAÇÃO DO JUSTO}

Toda ordem que encontramos na diversidade da existência, ou que nos empenhamos em fomentar, emprestou do direito o seu nome: falamos de leis da natureza, de leis da moralidade e de costume, de leis da lógica e da estética. Que posição ocupam entre todos esses tipos de leis, e, portanto, no todo, em nosso conhecimento de mundo, as leis no sentido primeiro da palavra, as leis do direito? A respeito da lei, Gustav Radbruch assevera que:

A cada atividade básica do espírito humano corresponde um tipo especial de leis do dever: a lógica trata das leis do modo de pensar verdadeiro, correto, científico; a estética trata da maneira certa de vivenciar com sentimento a arte e a beleza; todavia, o dever ético, que apresenta sua lei ao nosso querer agir, é de natureza tríplice: as regras de um agir bom, adequado e justo produzem a moralidade, o costume e finalmente o direito. (RADBRUCH, 1999, p. 1). 
Como enunciado de um observador, acredita-se que a fundamentação do direito em Gustav Radbruch é uma questão central e essencial a toda vida em sociedade. Por sua vez, o problema da aplicação da lei injusta é muito mais um problema prático; um problema, aliás, inevitável do agir humano, que pertence mais à ética do que o próprio direito. A ideia de direito proposta pelo autor não é outra coisa senão a justiça (o direito é a realidade cujo sentido é servir à justiça).

A ideia de justiça adotada pelo autor baseia-se no princípio da igualdade, fazendo transparecer as influências aristotélicas de Radbruch. O justo, assim como o bom, o verdadeiro e o belo, é absoluto, ou seja, é um valor que não deriva de nenhum outro valor. Mas esta noção de justiça como igualdade, embora absoluta, é uma ideia formal, razão pela qual Gustav Radbruch irá inserir, em seu conceito de direito, outros dois elementos: o fim e a segurança jurídica.

Sendo a justiça apenas a forma do direto, Radbruch acrescenta a este um princípio material, a ideia de fim ou finalidade, que toma seu conteúdo da ética. O princípio da finalidade atuará no conteúdo do direito de modo relativo, dependendo do valor moral a que fizer referência. A ética, que se divide em teoria dos deveres morais e em teoria dos bens morais, identifica três tipos de valores diferentes: os valores individuais, os valores supra-individuais e os transpessoais.

Embora já afirmado, o direito deve se basear em critérios fundamentalmente seguros e racionais, para só assim posicionar-se no sentido de afastar do meio social não só a sensação de incerteza, mas principalmente a sensação de injustiça. Nesse aspecto, o crescente valor que se atribui à segurança jurídica revela o reconhecimento de que ela é exigência fundamental até para as ideologias jurídicas orientadas exclusivamente pelo bem comum. E mais, ainda que uma lei positiva não se alicerce nas exigências da justiça ou da conformidade a fins, busca de alguma forma, um valor: a segurança jurídica.

De fato, é impossível traçar uma linha precisa entre os casos em que a lei escrita deve dar lugar à justiça e aqueles onde uma lei precisa ser reconhecida como válida a despeito de seu conteúdo danoso e injusto. Há, porém, uma linha distintiva que pode ser traçada com absoluta clareza: se a igualdade, que é o cerne da justiça, é repudiada deliberadamente ao editar-se uma regra de direito positivo, então a regra não só é injusta, mas não possui a verdadeira natureza de direito, porque este não pode ser definido senão como uma instituição ou ordem das relações humanas cujo sentido e propósito é servir à justiça. 


\section{INJUSTIÇA LEGAL X DIREITO SUPRALEGAL}

Na concepção de Gustav Radbruch, o positivismo desarmou os juristas frente a leis de conteúdo arbitrário e delituoso. Utilizando-se do princípio (“a lei é a lei”), máxima do positivismo (que não conhecia qualquer limitação), o regime nazista manipulou seus juízes e perpetrou as mais terríveis atrocidades sob a proteção da legalidade. Termos como "arbitrariedade legal" ou "direito supralegal” eram contradições em si (RADBRUCH, 1980, p. 21-22).

De maneira geral, Gustav Radbruch analisa que o positivismo é incapaz de fundar, com suas próprias forças, a validade das leis, uma vez que confunde a validade com a mera confirmação da vigência. No entanto, isso não significa que deva ser de todo abandonado, pois "toda a lei positiva já traz consigo um valor - uma lei é sempre melhor que nenhuma lei -, independente de seu conteúdo, pois ao menos cria segurança jurídica” (RADBRUCH, 1980, p. 35-36).

Pois bem, o conflito existente entre segurança jurídica e justiça, ou seja, entre uma lei positiva discutível quanto ao conteúdo e um direito justo não positivado, se apresenta, em verdade, como um conflito da justiça consigo própria, pois trata-se de um conflito entre justiça aparente e justiça verdadeira. É através desta análise que Gustav Radbruch propõe, nos seguintes termos, sua reconhecida formulação:

O conflito entre a justiça e a segurança jurídica poderia ser bem solucionado no sentido de que o direito positivo estatuído e assegurado pelo poder tem prevalência, ain da que por seu conteúdo seja injusto e inconveniente, salvo quando o conflito da lei positiva com a justiça alcance uma medida tão insuportável que a lei, como direito injusto, deva ceder lugar à justiça (RADBRUCH, 1980, p. 37).

Na base dessas constatações, Gustav Radbruch esclarece que é impossível traçar uma linha exata quanto ao que difere a arbitrariedade legal de uma lei válida, porém com conteúdo injusto. Mas, há, sim, uma outra delimitação que pode ser feita com absoluta exatidão. E esta se refere aos casos em que não se pretende alcançar a justiça, nos quais a igualdade que constitui a medula da justiça é negada claramente pelo direito positivo. Nesses casos, "não somente o direito é injusto, mas também carece de qualquer natureza jurídica”. (RADBRUCH, 1962, p. 38). 
Entretanto, assinala o jusfilósofo alemão que as leis de conteúdo muito injusto, mesmo que vigentes pelos critérios do ordenamento jurídico a que pertencem, perdem sua natureza jurídica, deixando de ser direito. A modificação no status da lei não se dá na vigência, mas, sim, na validade.

Da mesma forma, não se pode definir o direito, inclusive o direito positivista, de outra forma senão como uma instituição que, por seu próprio sentido, está determinada a servir à justiça. Todavia, conclui-se que, adotando-se estes padrões, setores inteiros do direito nazista jamais atingiram a qualidade de direito. Numa análise histórica, assim como a personalidade de Hitler, o direito nazista se caracterizava por uma completa falta de sentido, de verdade e de direito, e estava baseado no exato oposto do elemento essencial à justiça: o tratamento igualitário. Como consequência disso, carecia totalmente de natureza jurídica, não era um direito talvez injusto, não era direito sob nenhum aspecto.

Isto é especialmente válido para todas as legislações que denominavam alguns homens de sub-homens, negando-lhes direitos humanos. Outro exemplo de legislações que sequer chegaram a possuir natureza jurídica eram as cláusulas que previam indistintamente as mesmas punições para os mais diferentes delitos, sem consideração de quaisquer variáveis, permitindo a aplicação da mesma pena (em muitos casos a morte) para o cometimento de delitos com as mais diversas naturezas e gravidades.

A esse respeito, Gustav Radbruch reconhece especialmente após doze anos de experiência nazista, que o conceito de arbitrariedade legal - e a negação da natureza jurídica que esta pode gerar em leis de conteúdo insuportavelmente injusto -, significa terríveis perigos para a noção de segurança jurídica (RADBRUCH, 1980, p. 40-41). Entretanto, pontua sua esperança de que as arbitrariedades cometidas sejam um desvio jamais repetido pelo povo alemão, e alerta que é preciso prevenir o retorno das arbitrariedades através da superação fundamental do positivismo.

\section{A INCESSANTE BUSCA DO EQUILÍBRIO ENTRE A POSITIVIDADE DO DIREITO E A REALIZAÇÃO DA JUSTIÇA}

Gustav Radbruch nunca foi um positivista pleno, pois sempre considerou problemática a aplicação da lei com conteúdo injusto ou imoral. Prova disso é a sua afirmação, em 1914, de que 
"não se pode conceber nenhuma justificação para a vigência do direito manifestamente injusto" (KAUFMANN, 2002, p. 65-66). Muitos autores defendem que Gustav Radbruch, apesar de abandonar o positivismo em 1945, nunca modificou suas noções acerca da filosofia e do conceito de direito. É certo que ele foi o responsável pela reabilitação da filosofia do direito, ao superar o conflito entre as posições estanques do positivismo e do direito natural.

Depois de 1945, Gustav Radbruch continuou a operar com o mesmo conceito de direito. Entretanto, a partir da constatação de que o positivismo é incapaz de explicar a validade do direito através da separação absoluta entre direito e moral e, verificando as consequências morais da aplicação desta teoria no contexto da Alemanha nazista, o autor fez uma importante inversão na relação existente entre os elementos de seu conceito de direto.

Robert Alexy, um dos autores contemporâneos que mais se ocupa da Fórmula de Radbruch, afirma que aquele que sustenta a Fórmula abandona a tese positivista. Os ensinamentos de Radbruch são especialmente valiosos para a teoria da validade de Alexy, desenvolvida no Begriff und Geltunhgdes Rechts, onde a Fórmula de Radbruch integra seu conceito de direito não positivista, sob a denominação argumento da injustiça. Em seus textos, Robert Alexy utiliza-se de até quatro versões da fórmula, dependendo da extensão adotada. A forma mais breve e simplificada é "a injustiça extrema não é direito"; a mais extensa é:

O conflito entre a justiça e a segurança jurídica deveria poder solucionar-se no sentido de que o direito positivo afiançado pela promulgação e a força tenha também preferência quando seja injusto e inadequado quanto ao conteúdo, a não ser que a contradição entre lei positiva e justiça alcance uma medida tão insuportável que a lei deva ceder como "direito injusto" ante a justiça (ALEXY, 2004, p. 227-228).

Não é demasiado referir que Robert Alexy entende que a fórmula radbruchiana, em uma versão mais extensa, divide-se em duas partes ou subfórmulas (intolerância e negação). A fórmula da intolerância se dá pela afirmação de que as leis positivas perdem sua validade jurídica quando sua contradição com a justiça se dá em medida insuportável. A fórmula da negação surge com a idéia de que as leis que negam, de forma consciente, a igualdade, núcleo da justiça, perdem sua própria natureza jurídica (ALEXY, 2004, p. 228).

Enquanto a fórmula da intolerância, que é a mais aplicada pela jurisprudência, possui um caráter objetivo, pois aplica a fórmula da injustiça, a fórmula da negação possui um caráter subjetivo, pois diz respeito aos propósitos e às intenções do legislador. Por esta diferença, Robert 
Alexy assinala que é possível imaginar casos em que ambas as fórmulas levem a resultados diferentes. Por exemplo, um legislador que busca a igualdade e, entretanto, leva a cabo uma injustiça insuportável, e outro que deseja realizar o injusto, mas não o faz na medida do insuportável.

Em regra, ao se falar de uma injustiça insuportável, deveriam coincidir resultado e intenção, podendo-se falar, então, de uma sobreposição (overlapping) de ambas as fórmulas. Todavia, Robert Alexy entende que a fórmula radbruchiana pressupõe um direito suprapositivo, no sentido de que a aplicação da fórmula conduz a uma fundamentação que se utiliza de princípios jurídicos que não estão positivados (ALEXY, 2004, p. 217).

Em outras palavras, para Robert Alexy, a característica de destaque da fórmula radbruchiana é que esta não exige uma coincidência completa entre direito e moral, uma vez que permite que o direito positivado e eficaz seja válido mesmo que seu conteúdo seja injusto; já Gustav Radbruch não exige uma orientação da totalidade do direito à moral, mas, sim, incorpora ao direito um limite externo (ALEXY, 2004, p. 228-229).

Enquanto os positivistas (que adotam a teoria da separação entre direito e moral) trabalham com um conceito de direto baseado somente na legalidade conforme o ordenamento e na eficácia social, sendo indiferente o conteúdo do direto, como o prova a célebre frase de Hans Kelsen, "portanto, qualquer conteúdo pode ser direito" (ALEXY, 2004, p. 229); os não positivistas que seguem a fórmula radbruchiana permanecem adotando a legalidade segundo o ordenamento e a eficácia social, entretanto, incorporarão um terceiro elemento ao seu conceito de direito, qual seja, a correção material do conteúdo como critério limitativo.

$\mathrm{O}$ abandono do positivismo em sentido axiológico teve como consequência mais radical a doutrina da subordinação da lei à justiça. No "Quinto minuto de Filosofia do Direito", escrito por Gustav Radbruch, temos que:

Há também princípios fundamentais de todo direito que são mais fortes do que todo e qualquer preceito jurídico positivo, de tal modo que toda lei que os contrarie não poderá deixar de ser privada de validade. Há quem lhes chame direito natural e quem lhes chame direito racional. Sem dúvida, tais princípios acham-se, no seu pormenor, envoltos em graves dúvidas. Contudo, o esforço de séculos conseguiu extrair deles um núcleo seguro e fixo, que reuniu nas chamadas declarações de direitos do homem e do cidadão, e fê-lo com um consentimento de tal modo universal que, com relação a muitos deles, só um sistemático cepticismo poderá levantar dúvidas (RADBRUCH, 1974, p. 474). 
De tal maneira, Gustav Radbruch atinge o ponto máximo de seu racionalismo com a afirmativa conclusiva de que os direitos humanos estão abrigados em normas supra-estatais, a que qualquer Direito Positivo deve se coadunar, sob pena de ser considerado inválido. Por fim, Gustav Radbruch critica a ordenação jurídica nazista com fulcro na respeitabilidade e imposição forçosas dos valores jurídicos e dos direitos humanos supra-estatais, os quais afastam de vez qualquer pretensão positivista de justificar todo totalitarismo. Ainda assim, a priorização material da justiça na segunda fase do pensamento radbruchiano foi uma necessidade histórica e social de honorabilidade aos direitos humanos a partir do reconhecimento de que só a justiça e o conjunto dos Direitos Humanos postos como prioridade efetivada pelo Estado, seriam capazes de realizar a correta acepção dos direitos humanos que deveriam ser positivados como fundamentais (legais) garantidos às pessoas humanas.

\section{CONSIDERAÇÕES FINAIS}

Diante de todas as considerações abordadas, emblematicamente, o presente trabalho procurou trazer para o mundo do direito o desenvolvimento de uma "metodologia adequada" e não a "metodologia correta", porque pode haver diversas metodologias jurídicas "corretas", as quais naturalmente se contactam e entrecruzam sob múltiplos aspectos. Nesse sentido, ao se analisar o reflexo da aplicação da "lei injusta" na sociedade, compreende-se que a preocupação maior de Gustav Radbruch passa a ser a tentativa de extrair indutivamente o conceito de direito das manifestações jurídicas individuais, e não há dúvida que, em princípio, é possível alcançar o conceito geral mediante a comparação das manifestações jurídicas individuais.

Porém, é importante observar que mesmo através da "mera" aplicação do direito, a lei desenvolve-se para se manter lei. Assim, os diferentes modos de determinação do direito, na verdade, não se distinguem qualitativamente, mas sim pelo grau de extensão da lei. Nesse aspecto, a lei não pode e não deve ser formulada univocamente, pois é criada para casos cuja variedade é infinita. Porém, veja-se que uma lei fechada em si, acabada e sem lacunas (na medida em que tal fosse possível) levaria a paralisação do desenvolvimento do direito. Na realidade, os conceitos legais não se desenvolvem apenas mediante meras abstrações factuais, mas são formulados mediante conceitos-tipo, conceitos ordenadores, em que não se verifica um tudo ou nada, mas sim um mais ou menos. 
Evidentemente, um dos problemas cardeais no direito é sempre a escolha de um método. Por isso, se com base no que foi dito se chegar à conclusão de que o legislador se deve abster, tanto quanto possível, de conceitos fortemente normativos e indeterminados, especialmente cláusulas gerais, então isso é um princípio correto, que não deve, contudo, conduzir ao erro de pensar que os conceitos normativos se podem evitar totalmente. Como já foi explorado neste trabalho, o direito tem de regular, tem de encontrar uma ordem de dever, o que não é possível com conceitos puramente empíricos.

Nesses casos, não somente o direito é injusto, mas também carece de qualquer natureza jurídica, isto é, as leis de conteúdo muito injusto, mesmo que vigentes pelos critérios do ordenamento jurídico a que pertencem, perdem sua natureza jurídica, ou seja, deixam de ser direito. Disso resulta que a modificação no status da lei não se dá na vigência, mas, sim, na validade. Desta maneira, conclui-se que a injustiça extrema não é direito. O ideal jurídico é ideal para o direito, e mais ainda para o direito de uma determinada época, de um determinado povo e para relações sociológicas e históricas muito específicas. Robert Alexy, através do seu conceito de direito, tem a pretensão de superar o modelo positivista da tese da separação total entre direito e moral e, para tanto, acrescenta aos já conhecidos elementos da legalidade conforme o ordenamento e da eficácia social, um novo e terceiro elemento, que possibilita a correção material do conteúdo jurídico, uma vez que o direito será permeado por elementos morais.

Independente do motivo escolhido, o qual não se tem aqui a pretensão de identificar, o tema em questão é, com absoluta certeza, um dos mais importantes trabalhos jurídicos do século XX e merece ser estudado em profundidade, como estudiosos de todo o mundo (à infeliz exceção do Brasil) têm feito há mais de meio século. De nossas considerações resultou que a justiça é a ideia específica do direito, suficiente para desenvolver o seu conceito, mas que, assim mesmo, a ideia de direito não se esgota na justiça, vai muito além do seu próprio horizonte.

\section{REFERÊNCIAS}

ALEXY, Robert. The argument from injustice. A reply to legal positivism. New York: Oxford University Press, 2002.
ALEXY, Robert. La decision deI Tribunal Constitucional Federal alemán sobre los homicidios cometidos por los centinelas deI Muro de Berlín. Buenos Aires: La Ley, 2004. 
ALEXY, Robert. Una defensa de Ia fórmula de Radbruch. Buenos Aires: La Ley, 2004.

ALEXY, Robert. Teoria da Argumentação Jurídica: a teoria do discurso racional como teoria da fundamentação jurídica. Tradução Zilda Hutchinson Schild Silva. Rio de Janeiro: Forense, 3. ed., 2011.

BAHIA, Charles Nunes. Positivismo jurídico e nazismo: a superação do mito. Disponível em: <http://www.ambito-juridico.com.br/site/?n_link=revista_artigos_leitura\&artigo_id=13626>. Acesso em: 27 jan. 2013.

BUCHWALD, Friedrich. Gerechtes Recht. Weimar, 1946.

COSTA MATOS, Andityas Soares de Moura. Estado de exceção e ideologia juspositivista: do culto do absoluto ao formalismo como garantia do relativismo ético. Revista da Faculdade de Direito da Universidade Federal de Minas Gerais. Ano 2009, nº 54. Belo Horizonte: UFMG, 2009.

DUSSEL, Enrique. Para uma Ética da Libertação Latino-Americana. Eticidade e Moral. São Paulo: Loyola, 1977.

GOYARD-FABRE, Simone. Os princípios filosóficos do Direito Político Moderno. São Paulo: Martins Fontes, 1999.

GOYARD-FABRE, Simone. Os fundamentos da orden jurídica. São Paulo: Martins Fontes, 2007.

KAUFMANN, Arthur. Derecho, moral e historicidad. Madrid: Marcial Pons, 2002.

KAUFMANN, Arthur; HASSEMER, Winfried (Orgs.). Introdução à filosofia do direito e à teoria do direito contemporâneas. Lisboa: Gulbenkian, 2002a.

KELSEN, Hans. Teoria pura do direito. São Paulo: Martins Fontes, 1998.

MARTÍNEZ BRETONES, Maria Virginia. Gustav Radbruch: Vida y Obra. Instituto de Investigaciones Jurídicas. México: Universidad Nacional Autónoma de México, 2003.

MARTINS, Fábio Henrique Araújo. Uma análise da ADPF 153 desde a fórmula de Radbruch e da jurisprudência da Corte Interamericana de Direitos Humanos. Revista Internacional de Direito e Cidadania, n. 9, p. 43-53, fev. 2011.

PAULSON, Stanley L. On the background and significance of Gustav Radbruch's Post-War papers. Oxford Journal of Legal Studies, v. 26, n. 1, p. 17-40, 2006. 
RADBRUCH, Gustav. Arbitradriedad legal y derecho supralegal. Buenos Aires: AbeledoPerrot, 1962.

RADBRUCH, Gustav. Gesetzliches Unrecht und übergesetzliches Recht. Prólogo. In:

Arbitrariedad legal y derecho supralegal. VÁZQUEZ, Maria Isabel Azaretto de. Buenos Aires: Abeledo-Perrot, 1962.

RADBRUCH, Gustav; SCHMIDT, Eberhard; WELZEL, Hans. Derecho injusto y derecho nulo. Iniciación jurídica. Madrid: Aguilar, 1971.

RADBRUCH, Gustav. Filosofia do Direito. Trad. de Luís Cabral de Moncada. Portugal, Coimbra: Armênio Amado, 1974.

RADBRUCH, Gustav. EI hombre em el derecho. Buenos Aires: Depalma, 1980.

RADBRUCH, Gustavo. Introdução à Ciência do Direito. Tradução Vera Barkow. São Paulo: Martins Fontes, 1999.

RADBRUCH, Gustav. Filosofia do Direito. São Paulo: Martins Fontes, 2004.

RADBRUCH, Gustav. Filosofia do Direito. São Paulo: Martins Fontes, 2010.

VÁZQUEZ, Maria Isabel Azaretto. Prólogo. In: RADBRUCH, Gustav. Arbitradriedad legal y derecho supralegal. Buenos Aires: Abeledo-Perrot, 1962.

VIGO, Rodolfo Luis. La injusticia extrema no es derecho (De Radbruch a Alexy). Buenos Aires: La Ley, 2004.

VIGO, Rodolfo Luis. La axiologia de Gustav Radbruch. In: La injusticia extrema no es derecho. Buenos Aires: La Ley, 2006. 